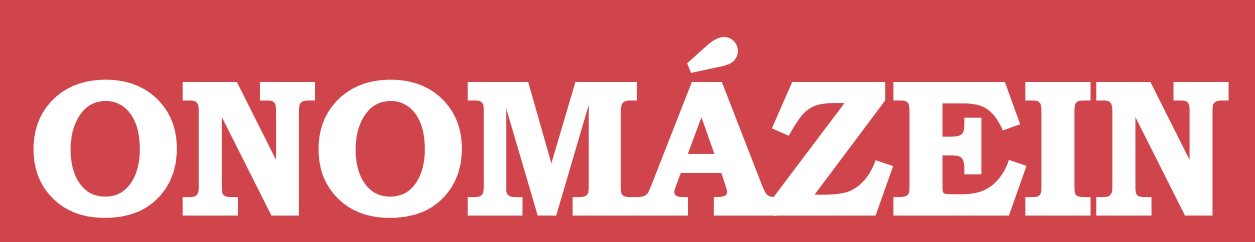

Revista de lingüística, filología y traducción
PONTIFICIA UNIVERSIDAD

\title{
Los tratados millcayac y allentiac (1607) de Luis de Valdivia. Noticia de un hallazgo bibliográfico
}

Luis de Valdivia's Millcayac and Allentiac treaties (1607). News of a bibliographic finding

\section{Nataly Cancino Cabello}

Universidad Nacional Autónoma de México México

\section{(c) $(i)$}

Nataly Cancino Cabello: Instituto de Investigaciones Filológicas, Universidad Nacional Autónoma de México, México. | Correo electrónico: nataly.cancino.cabello@gmail.com 


\section{Resumen}

En este trabajo informamos el hallazgo de Doctrina cristiana, catecismo y confesionario en las dos lenguas más generales que corren en la Provincia de Cuyo de Luis de Valdivia. Este volumen, impreso en Lima en 1607, contiene dos tratados: uno millcayac y otro allentiac. Para describir el ejemplar, primero, situamos la obra en la producción de su autor. En segundo lugar, estudiamos la historia huarpe y las lenguas millcayac y allentiac. Posteriormente, describimos la peregrinación de los fragmentos de esta edición que hasta ahora se conocían. Finalmente, a modo de propuestas de investigación, presentamos el volumen en comparación con la obra de Valdivia sobre el mapudungun (1606) y los "complementos pastorales" (1584-1585) del III Concilio Provincial de Lima.

Palabras clave: millcayac; allentiac; huarpes; Luis de Valdivia; lingüística misionera.

\section{Abstract}

In this paper, we report the discovery of Luis de Valdivia's Doctrina cristiana, catecismo y confesionario en las dos lenguas más generales que corren en la Provincia de Cuyo, which has two treaties, one Millcayac and other Allentiac. To describe the volumen, first, we place it in Valdivia's production. Secondly, we study the history of Huarpe people and their languages, Millcayac and Allentiac. Subsequently, we describe the pilgrimage of the fragments of this edition hitherto known. Finally, as research proposals, we present this volume, compared with Valdivia's work on mapudungun (1606) and III Provincial Council of Lima's "complementos pastorales" (1584-1585).

Keywords: Millcayac; Allentiac; Huarpe people; Luis de Valdivia; missionary linguistics. 


\section{Introducción}

En este artículo informamos el hallazgo de Doctrina cristiana, catecismo y confesionario en las dos lenguas más generales que corren en la Provincia de Cuyo de Luis de Valdivia, impreso en Lima, en 1607. Este volumen estuvo desaparecido hasta hace algunos meses, cuando lo hallamos en Roma, en el marco de la investigación posdoctoral "La reflexión sobre las lenguas indígenas en gramáticas y vocabularios misioneros de la Colonia de América” (Instituto de Investigaciones Filológicas, Universidad Nacional Autónoma de México, marzo 2015 a febrero 2017).

La pieza se inscribe en el conjunto de tratados misioneros elaborados para la colonización de los territorios del imperio español. Particularmente, su autor, Luis de Valdivia, orientó su trabajo hacia los mapuches, pero también escribió tratados catequéticos y lingüísticos en/sobre allentiac y millcayac, hablados por los huarpes de San Juan y de Mendoza, respectivamente, que identifica como lenguas generales de la Provincia de Cuyo, que pertenecía a la jurisdicción eclesiástica y civil chilena (actualmente es territorio argentino). Aunque Valdivia no visitó esa zona, conoció dichos idiomas a través de sus hablantes en Santiago de Chile, quienes habían sido "trasladados" para prestar servicio a encomenderos.

Este volumen es el único testimonio conocido de dos lenguas extintas desde finales del siglo XVII o inicios del XVIII, habladas por los huarpes, un grupo desaparecido. Además, la historia de la circulación de la obra engrandece el valor de este ejemplar: enviado al Prepósito General jesuita, permaneció en la Biblioteca del Colegio Romano aun cuando este debió abandonarse y, posteriormente, llegó a la Biblioteca Casanatense, donde se custodia hasta hoy. Su creación también es consecuencia de sucesos históricos: escrita por un jesuita español en Santiago de Chile, donde tuvo contacto con indígenas huarpes de la actual Argentina y donde describió sus lenguas, se imprimió en Lima, capital del Virreinato de Perú. Por lo tanto, es una valiosa fuente y objeto de estudio para la textualidad colonial. Se trata, sin duda, de un impreso interesante para historiadores, antropólogos, lingüistas y bibliógrafos, pero también para un público amplio, sensible ante el relato de las relaciones interétnicas en América. En estos aspectos, creemos, radica la valía de este impreso como patrimonio cultural.

Para describir el ejemplar, lo situamos en la producción misionera del autor. Posteriormente, nos centramos en algunos aspectos de la cultura huarpe y de las lenguas millcayac y allentiac. Asimismo, revisamos la pregrinación de los fragmentos del volumen que hasta la fecha se conocían. Por último, nos centramos en el ejemplar de Roma, que hemos hallado,

1 En la actualidad, hay personas en la zona de origen que se reconocen como huarpes. Por ello, Viegas Barros (2009) señala su pervivencia hasta nuestros días. Es posible que los descendientes vivan un proceso de etnogénesis. 
con especial énfasis en su estructura; asimismo, exploramos algunas posibilidades de interpretación desde una perspectiva comparativa, entre sí, con los complementos pastorales del III Concilio Limense (1582-1583) y con Arte mapudungun de Valdivia (1606). Debido a que es un primer acercamiento al volumen en su integridad, presentamos este trabajo a modo de propuesta para las investigaciones que esperamos suscite el hallazgo.

\section{Las obras misioneras de Valdivia}

Luis de Valdivia, SJ, llegó a Chile en 1593 con el primer grupo que la Compañía de Jesús envió a aquellas tierras. Su trabajo catequético, fundamentalmente orientado hacia los mapuches, estuvo enmarcado en su voluntad de ejecutar la "guerra defensiva", estrategia que promovió en los albores del siglo XVII para lograr la conquista espiritual de estos indígenas, atrayéndolos a la fe católica y a la Corona española, y reservando el belicismo solo si estos atacaban antes a los españoles. Con este fin, Valdivia elaboró Arte, y gramatica general de la lengva que corre en todo el Reyno de Chile, que dio a la imprenta en Lima en 1606, durante una de sus estancias, para dialogar con las autoridades virreinales sobre la situación chilena. Este Arte es la obra más difundida del autor, entre otros motivos, porque es el primer tratado actualmente conocido sobre el mapudungun².

La obra ofrece un importante aparato paratextual, inserto por disposiciones legales (aprobaciones y licencia) y por la tradición escrita impresa (dedicatoria y proemio). El cuerpo del texto es una miscelánea de tratados lingüísticos (arte y vocabulario) y textos catequéticos (confesionario, doctrina, catecismo), lo cual es común en los volúmenes misioneros, pues se pensaban como un conjunto que facilitara la práctica evangélica (Ridruejo, 2007).

El arte se refiere a la fonética y a la ortografía, al acento, a los verbos (conjugación y modos), a los nombres (relativos, numerales, de edad, de tiempo, de parentesco y afinidad), a los pronombres, a los adverbios, a las partículas, a las preposiciones e interjecciones. El "Vocabulario" se ciñe a la tradición y los vocablos se ordenan alfabéticamente. Los textos catequéticos, en tanto, son una adaptación a la cultura mapuche y una traducción al mapudungun de los "complementos pastorales" del III Concilio de Lima, un conjunto de tres obras producidas por resolución de dicho encuentro: Doctrina cristiana y catecismo (1584), Confesionario para los curas de indios (1585a) y Tercero catecismo (1585b). Estos textos -escritos en aymara, quechua y español- debían traducirse a los demás idiomas indígenas de la Archidiócesis, disposición que Valdivia cumplió para el mapudungun.

2 Posiblemente existió un trabajo previo, Diccionario de la lengua chilena y observaciones para aprenderla con mayor facilidad y elegancia de Gabriel de Vega, también jesuita, que se encuentra extraviado (Medina, 1897). 
Más tarde Valdivia vivió un verdadero destierro en Valladolid, con prohibición de la Compañía de volver a Chile, producto de su controversial actuación política. Allí publicó, en 1621, Sermon en lengva de Chile. En él, el jesuita generó un conjunto textual autónomo formado por una adecuación de los primeros nueve de los treinta y un sermones del Tercero catecismo (1585b) de los complementos pastorales (cfr. Cancino Cabello, 2015). Esta obra tuvo un alcance menor que el volumen de 1606 e incluso no está claro si se envió a Chile.

Valdivia no solo siguió las directrices limenses para la evangelización mapuche, sino también para la huarpe, de modo que imprimió en Lima, en 1607, Doctrina cristiana, catecismo y confess[i]onario en las dos lenguas más generales que corren en la Provincia de Cuyo, jurisdicción del Reyno de Chile. Este volumen contiene dos tratados: el primero, millcayac; el segundo, allentiac. Su impresor fue Francisco del Canto, el mismo que había estado a cargo del Arte mapudungun de 1606. Según Canals Frau (1940), Valdivia escribió este trabajo durante su primera estancia en Chile, entre 1593 y 1602, y, a juzgar por el "colofón” que aparece tras el arte allentiac, probablemente entre 1598 y 1599.

\section{Los huarpes: su historia y sus lenguas}

Millcayac y allentiac fueron dos parcialidades de una unidad etnológica mayor, huarpe, ubicada al este de la Cordillera de Los Andes, en el centro de la actual Argentina ${ }^{4}$. Estos indígenas hablaban, respectivamente, el millcayac y el allentiac. Se ha discutido si se trata de variedades dialectales o de lenguas. En la primera línea, Michieli (1990: 11-12) sostiene que "por su identidad morfológica, sintáctica y fonética se trata de dos dialectos o formas dialectatales [sic], con diferencia en parte del léxico y en algunas pautas de acentuación, de un mismo lenguaje que era conocido en general como 'huarpe'”; a su juicio, las diferencias son consecuencia del contacto con lenguas vecinas.

La segunda propuesta se fundamenta en el grado de mutua ilegibilidad y en que, si fueran dialectos, no se explicaría el esfuerzo de Valdivia por escribir dos tratados sobre la misma lengua, considerando que el autor tenía claridad de la variación dialectal, como lo demostró en el Arte del mapudungun (Díaz-Fernández, 2014). Por otra parte, esta idea se documenta en los paratextos del volumen de 1607, como la aprobación de Ciriacco Vello de Zarate (4r):

3 La única referencia al respecto aparece en Ramírez (1997), quien asegura que la edición llegó íntegra a Concepción, la diócesis más importante del sur chileno. Sin embargo, no se menciona la fuente, por lo cual el envío no nos consta.

4 Según Canals Frau (1973), hubo una tercera parcialidad, los puntanos, que ocupaban el actual territorio de San Luis. 
Por orden del Muy Reuerendo Padre Efteuan Paez Prouincial de la Compañía de Iefus en el Peru, vi eftas DoEtrinas Chiftianas y Cathezismos Confeflionarios, artes y Vocabularios, que el Reuerendo Padre Luys de Valdiuia de la dicha Compañia compufo en las dos lenguas generales, que corren en la Prouincia de Cuyo en las Ciudades de MendoÇa, y de fant Iuan. Y como perfona nacida y criada en aquella Prouincia, y q $\underline{\underline{e}}$ ambas lenguas Allentiac y Millcayac ${ }^{5}$, juzgo eftar muy propia la traduccion, y muy clara, y las reglas de ambas Artes muy vniuerfales y ciertas.

Lozano (1754: 165) ofrece otra prueba con el método de aprendizaje de Valdivia (práctica-errorcorrección de los naturales). Señala que el jesuita "consiguió en corto tiempo noticia cabal de la lengua alentiaca, que es esta de los huarpes. Después se aplicó con el mismo trabajo a aprender la milcaya".

Sobre la tipología, Loukotka (1968) incluye millcayac y allentiac en el grupo de lenguas y tribus andinas, en la rama D, subgrupo del sur, también compuesto por mapudungun, diaguita, humahuaca y lule. Por su parte, Greenberg (1987) clasifica millcayac y allentiac dentro del grupo amerindio, en el subgrupo de las lenguas chibcha-paezanas, específicamente, dentro de la rama paezana, formada por diversas lenguas aisladas y no clasificadas. La heterogeneidad de este grupo, no obstante, le ha valido numerosas críticas a su propuesta y creemos que no hay pruebas suficientes para esta clasificación. Es más, hasta la fecha, ningún parentesco parece bien demostrado (Viegas Barros, 2009).

Ahora bien, la cercanía entre millcayac y allentiac no está en duda7. Son varios los autores que, basándose en las obras de Valdivia (1607), destacan este hecho (Schüller, 1913a; Canals Frau, 1942b; Adelaar, 2004; Díaz-Fernández, 2002; Tovar, 1984). El mismo Valdivia (1607), en algunos pasajes del arte allentiac, remite al millcayac, de modo que se percata de la proximidad.

Por otra parte, es probable que los huarpes conocieran el mapudungun por el contacto con los mapuches; asimismo, eventualmente manejaron el quechua (Canals Frau, 1942a), aunque es posible que se haya abandonado tras el retroceso del imperio inca (Michieli, 1990). Valdivia $(\mathbf{1 6 0 6}, \mathbf{1 6 0 7 )}$ no da noticias al respecto, excepto cuando se refiere a la facilidad de aprender millcayac y/o allentiac para quienes conocieran mapudungun o quechua ${ }^{8}$, sin que

5 Destacado nuestro.

6 Ahora bien, indica que el millcayac era hablado por los puelches. Canals Frau (1942b: 160), sobre este asunto, sostiene que en Cuyo puelches y huarpes eran grupos "racial y lingüísticamente emparentados". En efecto, ya el mismo Valdivia (1607) había destacado, en el proemio de la obra, la proximidad del millcayac con el puelche.

7 Según Mitre (1894b), el allentiac es una lengua aislada, pues su léxico y gramática no se relacionan con idiomas vecinos. Esta opinión se debe a que desconocía, incluso, los fragmentos del millcayac, de modo que no pudo observar el parentesco.

8 Tovar(1984) se sirve de este comentario para relacionar allentiac y millcayac con las lenguas andinas. 
ello pueda interpretarse como el dominio de estos idiomas por parte de los huarpes, sino que más bien se refiere al bagaje previo de los misioneros y a la búsqueda de modelos de lenguas conocidas que facilitaran la enseñanza.

Al momento de los primeros contactos con los españoles, estos calcularon que la población huarpe llegaba a los treinta mil individuos(Lozano, 1755). Entonces, vivía un proceso de aculturación por influencia inca, iniciado en la segunda mitad del siglo XV (Canals Frau, 1942a, 1973). Los vocabularios de Valdivia (1607) así lo atestiguan (Zapater, 1992), pues recogen voces de origen quechua: mita, mill. y allen., 'vez', 'turno' < mit’a, quech. 'vez, turno'; muchaguina, mill. 'besar, yo beso', muchapianen, allen., 'yo beso', muč'a-, quech., 'besar' (cfr. Adelaar, 2004). Para Zapater (1992), otra prueba es la voz curaca en allentiac en Valdivia (1607) (también en millcayac).

Sin duda, la obligación de los mitimaes perjudicó a los huarpes, pero el mayor impacto lo generó el "traslado" a Chile: bajo el amparo de las atribuciones que daba a la Audiencia chilena la jurisprudencia sobre Cuyo, numerosos huarpes fueron encomendados a vecinos de Santiago desde épocas tempranas, por la necesidad de los conquistadores de conseguir mano de obra, la cual les era negada en Chile por el número insuficiente de indígenas en la zona central y por la belicosidad de estos (Michielli, 1994). Más tarde, encomenderos de Cuyo “rentaron" huarpes a sus pares en Santiago (Lozano, 1755). También pasaron encomiendas a la ciudad de La Serena, como señala Canals Frau (1940), para los primeros momentos de la Conquista, y Medina (1918b), para la segunda mitad del XVII.

Posteriormente, aun con la fundación de las ciudades cuyanas, la situación no era propicia, pues ya se había modificado el sistema socioeconómico huarpe (una economía de pesca, caza y mediana agricultura), de modo que Santiago ofrecía mayores posibilidades (Canals Frau, 1973). Por otra parte, el traslado a Chile impactó en la distribución espacial indígena en Cuyo, lo que produjo, como primera consecuencia, el despoblamiento de los valles centrales, donde se concentraba la mayor parte de la población, y, al mismo tiempo, la ocupación de zonas marginales, como el complejo lagunero de Guanacache, que ofrecía alimento y resguardo para evitar el éxodo; asimismo, los trasladados en su mayoría eran varones en edad productiva y en Cuyo se quedaron mujeres y niños, que se mestizaron entre la población hispana (Michieli, 1990). Más adelante, desde mediados del siglo XVIII, los huarpes debieron vivir en pueblos de indios; pese a que estaban en su lugar de origen, la rápida aculturación y las condiciones a las que se veían expuestos apresuraron su extinción (Canals Frau, 1973).

El traslado se ejecutaba con crueldad: atados y a veces incluso en colleras (Lozano, 1755), muchos indígenas morían en el camino (Canals Frau, 1973). En tanto, en Chile, los huarpes

9 Para 1609, cuando entra la Compañía de Jesús a Cuyo, quedaban ocho mil (Lozano, 1755). 
trabajaron, fundamentalmente, en tareas de minería y construcción (Canals Frau, 1940); sus condiciones eran precarias, por lo cual debían ser sustituidos por otros huarpes trasladados (Lozano, 1755). Suponemos que su posición marginal en la vida colonial chilena provocó una aculturación rápida.

De hecho, creemos que la falta de datos completos sobre estos indígenas es indicativa de su lugar secundario en los intereses coloniales. En ese sentido, si los mapuches constituían un asunto marginal para la Corona y solo se consideraban cuando peligraban los intereses reales ${ }^{10}$, ¿qué podía esperarse de las políticas sobre los huarpes? No solo eran grupos bárbaros que hablaban lenguas exóticas, no solo habitaban una zona alejada y de difícil acceso, sino que, además, estaban trasplantados, eran dóciles ante la conquista y vivieron un rápido proceso de aculturación.

\section{Los tratados millcayac y allentiac}

Luis de Valdivia tomó contacto con los huarpes en Santiago de Chile, fundamentalmente, a través del proceso de evangelización, según refiere Ovalle (1646). Ahora bien, es probable que Valdivia no haya sido el encargado directo de su catequesis, pues, cuando los primeros jesuitas se instalaron en Santiago de Chile, se encontraron con una sociedad formada por diversos grupos étnicos, ante lo cual se dividieron las tareas de acuerdo con estos criterios preestablecidos. En la repartición, Valdivia quedó a cargo de la catequesis de los mapuches, mientras que de los huarpes se responsabilizó Hernando de Aguilera (Foerster, 1996). De todos modos, Valdivia se interesó por los huarpes desde una perspectiva catequética y, de manera concomitante, por su lengua. Así, estos se convirtieron en sus informantes lingüísticos (Lozano, 1754), gracias a lo cual Valdivia obtuvo los insumos para la elaboración de su obra de 1607. Ahora bien, el contacto no se produjo con la misma facilidad, abundancia y regularidad que los encuentros con los mapuches (Márquez Miranda, 1943), un hecho que no es de extrañar si tomamos en cuenta la posición de los huarpes en la vida colonial santiaguina.

Según Ridruejo (2007), las obras millcayac y allentiac tuvieron una escasa difusión, como consecuencia de la extinción de las lenguas. El hecho de que encontremos en la actualidad una sola copia completa corrobora este dato. Sin embargo, de acuerdo con la información obtenida de los paratextos editoriales, ambas parecen haber preocupado a los misioneros, motivados por la docilidad, el servicio a los españoles y la falta de evangelización de sus hablantes.

10 En primer lugar, porque, en su lógica de subordinación, no se podía aceptar el belicismo mapuche (Salinas, 1991); en segundo lugar, porque La Araucanía ofrecía una entrada al continente a adversarios extranjeros, quienes podían aliarse con los mapuches (Díaz, 2010). 
Debido a que hasta ahora no se conocía el volumen completo, se llegó a pensar que los tratados millcayac y allentiac eran impresos independientes. Ridruejo (2009) propuso que algunos ejemplares se publicaron por separado, pues están dirigidos a públicos potencialmente distintos (al tratar lenguas diferentes) y porque cada tratado posee paratextos propios. Sin embargo, el confesionario y el arte allentiac se complementan con sus pares millcayac, y una impresión de esta clase habría exigido censura y licencia independientes. Al respecto, cabe plantearse la posibilidad de que los componentes de ambos tratados (doctrina, catecismo, confesionario, gramática y vocabulario) pudieran estar pensados para circular por separado, ya que contienen portadas internas y una copia de la licencia de impresión. Estas opciones abren otra interrogante: ¿por qué se imprimieron volúmenes integrados? Sobre lo que sí tenemos certeza es que los tratados millcayac y allentiac siguieron caminos separados.

\subsection{El tratado millcayac}

Debido a la confusión de los catálogos bibliográficos y a la ausencia de pruebas concretas, José Toribio Medina (1894: 55) pensaba que el tratado millcayac "no llegó a publicarse". En la misma línea, Mitre (1894: 38) señalaba que "el [arte] relativo á la lengua Milcayac, estaba pronto para darse á la estampa en 1607; pero como en ese mismo año emprendió Valdivia su primer viaje á España, el manuscrito debió quedar en Lima y se ha perdido". Sin embargo, en 1918 Medina indica que tiene ante sí "unos fragmentos de la Doctrina cristiana en lengua millcayac, de la cual ninguna muestra hasta ahora se había hallado" (1918a: v) y los publica. La edición que ofrece procede de unas fotografías de los originales descubiertos en el Harvard College (cuya procedencia se desconoce), que le hizo llegar Henry L. Janes, ex secretario de la Legación de Estados Unidos en Chile. Con esta edición, Medina pretende completar la edición que había hecho de la obra allentiac en 1894 (cfr. § 4.2).

Los fragmentos se reducían a dos hojas: la portada del confesionario y, en el vuelto, la licencia de impresión; la hoja 12 de la doctrina con un fragmento de los mandamientos y, en el vuelto, de las obras de misericordia. Consciente de que el material con que contaba era escaso, Medina (1918b: xiii-xiv) se preguntaba: “¿Será posible con solos estos elementos obtener una reconstitución de la obra toda, valiéndonos para ella de un procedimiento análogo al que suelen emplear en casos parecidos 'los paleontógos' que con disponer de una sola muela logran dar formas al animal del que procede?". Aunque el mismo autor reconoce la dificultad de esta tarea, pues se mueve en un terreno distinto al "orden natural" (Medina, 1918b: xiv), creía que contar con el modelo del allentiac, al cual podría asemejarse, y con saber que el volumen contenía gramática, vocabulario, catecismo y confesionario, podrían ayudar en la tarea. De hecho, la hipotética reconstrucción que propone de toda la obra millcayac es bastante cercana a la que conocemos, pues su decisión de basarse en la allentiac fue correcta: hoy sabemos que ambos tratados tienen la misma estructura. 
Al término de la "Noticia bibliográfica, histórica y etnográfica" con que Medina (1918b) presenta los fragmentos, da cuenta de una comunicación de R. Lehmann-Nitsche donde se le informó la publicación anterior de los mismos, en 1913, por parte de Rudolph R. Schüller, y de una nota sobre el millcayac del mismo autor (Schüller, 1913a y 1913b, respectivamente). Sin embargo, el bibliófilo decidió seguir adelante con la publicación del facsimilar para llegar a un público que pudiera tener dificultades en acceder a estos textos.

En efecto, Schüller publicó estas dos páginas en 1913. Las había ubicado el Prof. Leo Wiener en un libro sobre historia de México, en la Biblioteca de Harvard, y, posteriormente, fueron custodiadas por un bibliotecario. Schüller (1913a) ofrece, en primer lugar, una nota bibliográfica, en la que recoge la discusión de Medina (1894b) sobre la edición del allentiac y millcayac, y reconoce que el papel en que se imprimieron ambos tratados es similar. A su juicio, era posible suponer la existencia del arte millcayac, por los datos que ofrecía el mismo Valdivia (1607) en el tratado allentiac, donde se refería a dos artes y daba indicaciones de acuerdo a la gramática del millcayac (Schüller, 1913a). Este investigador es, entonces, el primero en informar sobre la existencia del tratado millcayac impreso.

A continuación, Schüller (1913a) presenta la reproducción facsimilar de las páginas halladas, tras la cual ofrece una transliteración con criterios paleográficos, junto con la misma página correspondiente al tratado allentiac. Al igual que Medina (1918b), presupone la similitud de ambos tratados, pero, también, con el arte del mapudungun de 1606. Se percata que al confesionario millcayac le sigue el decreto de la Real Audiencia, mientras que al allentiac también lo acompaña la licencia de Esteban Páez. También nota diferencias en la paginación, lo cual, a su juicio, "depends principally upon the larger type of letters employed in the Millcayac print” (Schüller, 1913a: 248).

En 1942, Salvador Canals Frau (1942b) reprodujo los mismos fragmentos que Schüller y Medina. Junto con el estudio previo, ofrece un breve vocabulario millcayac, tomando como base las dos páginas de Valdivia (1607) y la propuesta de Schüller (1913a), en la cual nota algunas deficiencias que pretende mejorar (interpretación, uso de grafías equivocadas), mediante la comparación de los fragmentos con el tratado allentiac.

Posteriormente, en 1943, Fernando Márquez Miranda anuncia "a los especialistas en las 'ciencias del hombre'” (61) el hallazgo del tratado millcayac en la Biblioteca de la Universidad de Cuzco. Se trataba de un ejemplar hasta entonces único al cual el investigador accedió tras la revisión del “Catálogo de la Biblioteca Jesuita” de 1938. En la misma publicación ofrece los textos fotografiados en una página de $23 \mathrm{~cm}$, en la cual incorpora cuatro folios de 8,5 cm por 5 cm cada uno, con lo cual afectó la legibilidad y el acceso a la obra (Díaz-Fernández, 2014). No obstante, el conocimiento del tratado ha sido posible hasta ahora por esta reproducción y los estudios lingüísticos sobre el millcayac (Zwartjes, 2000; Ridruejo, 2009; Díaz-Fernández, 2014) han debido tomarla como referencia. 
En el curso de nuestra investigación, no hemos localizado este ejemplar, que ni siquiera se encuentra en el catálogo actualizado y digitalizado de la Biblioteca Jesuita de la Universidad Nacional San Antonio Abad. Esperamos que no se trate de otra pérdida, como ha sucedido con otros materiales del pasado (incluido el tratado allentiac que Medina halló en Lima y que pronto, sin embargo, se perdió) y que se encuentre en alguna otra dependencia universitaria. Nos aferramos a esta posibilidad, pues el mismo Márquez Miranda (1943) abogó para que la obra se pusiera a mayor resguardo.

\subsection{El tratado allentiac}

José Toribio Medina dio las primeras noticias sobre su existencia en 1878, en su Historia de la literatura colonial de Chile (1878a, 1878b), pues había encontrado un ejemplar del tratado allentiac en la Biblioteca de Lima, pero este desapareció algunos años después. En 1892, el Conde la Viñaza, en su obra Bibliografía Española de las lenguas indígenas de América, dio a conocer la existencia de otro ejemplar en la Biblioteca Nacional de Madrid. Con anterioridad, varios autores habían ofrecido noticias confusas sobre la obra, cuyas propuestas son recogidas por Medina (1894b).

En 1894, Medina ofrece la edición de la copia de Madrid, única conocida entonces. Señala que pese a pretender una edición fotolitografiada, esta no fue posible debido al mal estado en que se encontraba el ejemplar, de modo que ha debido ofrecer "una reproducción a plana y renglón, conservando en absoluto la ortografía de la edición príncipe, y sin más alteraciones que una que otra corrección de las erratas del castellano" (Medina, 1894a: ix). A la fecha, la obra no aparece en el catálogo electrónico de la Biblioteca Nacional de España, como ya hacía constar Ridruejo (2009).

En 1940, Salvador Canals Frau ofrece una nueva edición del tratado allentiac. El autor considera la obra una "rareza", debido a que solo se conservaba un ejemplar en Madrid, y la misma categoría da para la edición de Medina de 1894, pues de ella se imprimieron 200 ejemplares, de los cuales 2 o 3 estaban en Argentina, mientras que ninguno había en la región de Cuyo, "principal interesada por tratarse de una lengua que antes se hablaba en su territorio" (Canals Frau, 1940: 19). Por ello, el rector de la Universidad de Cuyo, Dr. Edmundo Correas, gestionó el envío de un ejemplar desde Chile, el cual utilizó Canals Frau para su edición. Por lo anterior, esta se hizo sin consultar el que estaba en Madrid.

La presentación está inaugurada por una imagen facsimilar de la portada conocida en una página sin vuelta. Los criterios editoriales de Canals Frau (1940) alteran levemente la obra. En primer lugar, incorpora modificaciones que buscan subsanar los errores de imprenta de la segunda edición, pues, compartiendo el juicio de Shüller (1913b), considera que Medina no revisó lo suficiente las pruebas de imprenta. Así, corrige “cuchach eupl” (Valdivia, 
1894 [1607]: 74V), 'pan nuestro', por "cuchach cupi” (Canals Frau, 1940: 26); cotejando con la edición de 1607 adjudicamos la causa a un problema de lectura debido a la expansión de la tinta. Por otro lado, algunas modificaciones debidas a supuestos errores en la edición de 1894, según hemos constatado, son consecuencia de la fidelidad al original, que ya los presentaba. Por ejemplo, cambia "tucug” (Valdivia, 1894 [1607]: 6r) por "tucum” (Canals Frau, 1940: 31), pero Medina se ha limitado a copiar el "tucug" de Valdivia (1607: [78r]). Ahora bien, aun sin conocer la edición de 1607, el investigador se percató, por ejemplo, de que "zchillca” (Valdivia, 1984 [1607]: 5r) es "un error de Valdivia, sin duda. Zchillca o zhillca, es 'seis' y no siete [...]. Lo correcto sería yemni gleu, que es 'siete”" (1940: 30). Otros problemas, en cambio, no se corrigen, sino que se señalan en nota, como el caso de "Oroc" (Valdivia, 1894 [1607]: 5r): "esta palabra, que significa 'cinco', va siempre con h, horoc. El texto de Medina lo trae así, sin h, en este lugar" (Canals Frau, 1940: 30); ante ello el autor plantea la duda sobre si el error es de Valdivia o Medina.

En segundo lugar, hay modificaciones que facilitan la lectura. Entre ellas encontramos: cambios de puntuación, cursivas en lugar de paréntesis en el texto en español para indicar origen allentiac de la palabra y corrección de términos por añadidura o supresión de letras (Canals Frau, 1940).

Actualmente, se conoce un nuevo ejemplar del tratado allentiac, ubicado en la John Carter Brown Library de Estados Unidos. Gracias a un proyecto que ha puesto on line varias obras de su acervo, contamos con una versión digitalizada de tan valioso tratado ${ }^{11}$. Según nos consta, se trata de un trabajo con la misma estructura de la parte allentiac del ejemplar que hallamos en Roma.

\section{El ejemplar de Roma}

Con la certeza de que los tratados millcayac y allentiac constituían un solo volumen, iniciamos la búsqueda del mismo. Para ello fue necesario conocer las circunstancias personales e históricas del autor al momento de la edición de la obra. Para 1607 Luis de Valdivia se encontraba en Lima, en conversaciones con las autoridades virreinales en la búsqueda de apoyos para su propuesta de guerra defensiva. Si bien Valdivia, con el paso de los años, vivió situaciones complejas, para la época que nos ocupa mantenía una conversación fluida con los virreyes e, incluso, viajó a España a entrevistarse con el rey, todo lo cual le permitió, pese a la oposición de encomenderos y políticos en Chile, implementar su política de guerra defensiva. Igualmente, tenía excelentes relaciones

11 Se puede acceder al volumen en: https://archive.org/details/doctrinachristiaoovald. 
con el Prepósito General jesuita en Roma, Claudio Acquaviva, de modo que, cuando nos planteamos hipótesis para rastrear la obra, buscar entre las pertenencias de Acquaviva fue la opción más probable. ¿A quién más un jesuita disciplinado podría querer agasajar con su trabajo más que al Padre General? ¿Quién sino él debía conocer el alcance del apoyo que había brindado al autor? ¿Con quién más querría Valdivia mantener la cordialidad en las relaciones? Chile, apartado y marginal del mundo colonial americano, era objeto de interés de Valdivia, un interés que, a través de Acquaviva, se representaba para toda la Compañía.

No obstante, como consecuencia de la disolución de la Compañía de Jesús por el Papa Clemente XIV en 1773 (hasta 1814), las posesiones del Colegio de Roma, donde debían estar las pertenencias de Acquaviva, se dispersaron. La mayoría de los libros y documentos del Colegio fueron a dar a la Biblioteca Nacional Italiana, Ia Pontificia Universidad Gregoriana de Roma y el Archivum Romanum Societatis lesu, que volvió a Roma en 1931 (Ser Pérez, 1998). No obstante, la obra que buscábamos no se encontraba en ninguna de estas instituciones. Por ello, decidimos visitar el edificio donde se ubicó el Colegio de la Compañía en Roma, donde actualmente en un ala funciona el Liceo Classico Statale "Ennio Quirino Visconti" y, en otra, dependencias del Ministero per i Beni e le Attività Culturalli de Italia. La fachada de la via di Sant Ignazio, frente al ex Colegio Romano, está ocupada en su mayoría por el edificio de la Cámara de Diputados. Al observar la arquitectura, nos percatamos de un pasaje elevado que une este edificio con la antigua casa jesuita, de modo que indagamos sobre el mismo y descubrimos que había sido una construcción dominica, donde se ubicó una biblioteca de esa orden.

Se trata de la Biblioteca Casanatense, la cual alberga una cantidad importante de los volúmenes que los dominicos romanos poseyeron. Fue inaugurada el 3 de noviembre de 1701 por disposición testamentaria del cardenal Girolamo Casanate (Napoli, 1620-Roma, 1700), quien dejó donaciones y órdenes para la gestión de una biblioteca abierta al público. Su edificación se llevó a cabo en el convento de Santa María Sopra Minerva, en Roma (Cavarra, 2005), erigido frente al que fuera el colegio jesuita.

Desde 1873, con la supresión de las órdenes religiosas en Roma, pasó a tener una gestión laica. Muy pronto su administración fue conjunta con la Biblioteca Nazionale Vittorio Emanuele II, que, inaugurada en 1876, funcionaba en el edificio vecino del ex Colegio Romano de los jesuitas (Cavarra, 2005). En él, los bibliotecarios habrían encontrado intacto el archivo jesuita, que se mantuvo en la casa de Roma después de la expulsión (Ser Pérez, 1998). Con el fin de facilitar las comunicaciones, se construyó el pasaje elevado entre ambas contrucciones. En 1891, la separación de la Biblioteca Casanatense del convento dominico será también física, pues se inauguró su propia entrada por la Via di Sant Ignazio 52 (Cavarra, 2005), donde funciona hasta la actualidad. 
Esta puerta nos condujo a Doctrina cristiana, catecismo y confesionario en las dos lenguas más generales que corren en la Provincia de Cuyo de Luis de Valdivia ${ }^{12}$. Para nuestra sorpresa, un hecho confirmó nuestra hipótesis: el libro está dedicado al Prepósito General jesuita, Claudio Acquaviva, con letra manuscrita en la portada del ejemplar. Presenta, además, información bibliotecológica que indica dos poseedores: Ia Biblioteca Casanatense y la Casa Profesa jesuita de Roma.

Según conversaciones con el personal de la Casanatense, no se conocen los criterios por los cuales algunas de las obras del Colegio Romano pasaron a la biblioteca, pero entre ellos estuvo el volumen que buscábamos. Se ubica en la sección "Rari", constituida probablemente en el periodo de entre guerras con el fin de asegurar la conservación de estos materiales (Aiello, 2005). Ahora bien, creemos que la rareza de este ejemplar ha motivado, en parte, el que haya permanecido oculto a los investigadores, pues fue catalagado bajo la categoría "quechua". No es difícil imaginar las causas de este error: se trata de una obra impresa en Lima, sobre lenguas desconocidas. Hemos advertido a la biblioteca sobre este asunto y, al menos en el catálogo electrónico, ya se ha solucionado: ahora la obra solo aparece bajo la categoría "spagnolo". También hemos dado a conocer su valor bibliográfico y se nos ha asegurado que el volumen se encontrará custodiado con mayores medidas de seguridad.

\subsection{Descripción del volumen}

El volumen titulado Doctrina christiana, cathecismo y confessonario en las dos lenguas mas generales que corren en la Prouincia de Cuyo, jurisdicion del Reyno de Chile de Luis de Valdivia, con pie de imprenta en Lima, 1607, por Francisco del Canto, está encuadernado en piel de color amarillo, probablemente de cerdo, con algún desgaste menor. Como era habitual en la época, la portada es del mismo papel que el resto de la obra. Mide 15 centímetros de alto por 10 de lado, aunque los laterales que dan hacia las páginas están doblados, de modo que a primera vista el ancho es de 9,2 por delante y 9,4 por detrás. Está completo y en buen estado de conservación, con algunas intervenciones de lectores. Cuenta con datos bibliotecológicos de su biblioteca actual, la Casanatense, y de la Casa Profesa Jesuita de Roma, de donde procede. Posee una dedicatoria manuscrita en la portada: "A nuestro Padre General Claudio Aqua Viva”, lo que le añade, a su valor bibliográfico, uno documental (cfr. Guibovich Pérez, 2000), pues informa sobre la circulación del ejemplar.

12 También hallamos un ejemplar del Arte de 1606 de Valdivia, completo y en excelente estado. Una copia se encuentra en la Biblioteca Nacional de Madrid, con el vocabulario incompleto. Otra, en la Universidad de Valladolid, completa, con anotaciones posteriores (usada por Emilio Ridruejo para la edición facsimilar de 2007). 
El volumen posee un total de 120 páginas, en las cuales los contenidos se ubican del modo siguiente:

\section{TABLA 1}

Esquema general de Valdivia (1607)

\begin{tabular}{|c|c|c|}
\hline UBICACIÓN & CONTENIDO & NOTA \\
\hline$[1 r]$ & Portada general & Para toda la obra, para ambas lenguas \\
\hline$[\mathrm{IV}]$ & & blanco \\
\hline$[2 r]$ & Decreto de la Audiencia de Lima & Para ambas lenguas \\
\hline$[2 v]-[3 r]$ & Aprobación de Melchor de Urbina & Para ambas lenguas \\
\hline$[3 \vee]$ & Licencia de Esteban Páez & Para ambas lenguas \\
\hline$[4 \mathrm{r}]-[4 \mathrm{~V}]$ & Aprobación de Ciriaco Vello de Zarate & Para ambas lenguas \\
\hline$[5 r]-[5 V]$ & Aprobacion de Ivan Pérez de Espinosa & Para ambas lenguas \\
\hline$[6 r]-[7 v]$ & $\begin{array}{l}\text { Dedicatoria del autor a Ivan } \\
\text { Pérez de Espinosa }\end{array}$ & \\
\hline$[8 r]-[8 v]$ & Al lector & Proemio \\
\hline$[9 r]-[14 \mathrm{~V}]$ & Doctrina Christiana y cathecismo & $\begin{array}{l}\text { Aunque se anuncia el catecismo, este } \\
\text { aparece después diferenciado con título } \\
\text { independiente, como texto autónomo }\end{array}$ \\
\hline$[15 r]-[19 v]$ & Breve cathecismo & \\
\hline$[20 r]-[20 v]$ & Acto de contrición & \\
\hline$[21 r]$ & Confessionario breve & Portada interna \\
\hline$[21 V]$ & Decreto de la Audiencia de Lima & Repetido \\
\hline$[22 r]-[36 r]$ & Confessionario millcayac & \\
\hline$[36 v]$ & Blanco & \\
\hline$[37 r]$ & $\begin{array}{l}\text { Arte y gramática en dos lenguas } \\
\text { de indios millcayac y allentiac }\end{array}$ & $\begin{array}{l}\text { Portada interna, anuncia ambas len- } \\
\text { guas pero solo viene arte millcayac }\end{array}$ \\
\hline$[37 \mathrm{~V}]$ & $\begin{array}{l}\text { Decreto de la Audiencia de Lima } \\
\text { Licencia de Esteban Páez }\end{array}$ & Repetido \\
\hline$[38 r]-[60 r]$ & Arte de la lengua Millcayac & \\
\hline$[60 v]$ & Tabla de contenidos del arte & \\
\hline$[61 r]$ & Vocabulario breve en lengua millcayac & Portada interna \\
\hline
\end{tabular}




\begin{tabular}{|c|c|c|}
\hline$[61 v]$ & $\begin{array}{l}\text { Decreto de la Audiencia de Lima } \\
\text { Licencia de Esteban Páez }\end{array}$ & Repetido \\
\hline$[62 r]-[72 r]$ & Vocabulario breve en lengua millcayac & \\
\hline$[72 V]$ & & blanco \\
\hline$[73 r]$ & $\begin{array}{l}\text { Doctrina Christiana, cathecismo, con- } \\
\text { fesionario, arte y vocabulario allentiac }\end{array}$ & Portada interna \\
\hline$[73 \vee]$ & Decreto de la Audiencia de Lima & Repetido \\
\hline$[74 r]-[80 r]$ & Doctrina christiana en lengua allentiac & \\
\hline$[80 r]-[85 r]$ & Cathecismo & \\
\hline$[85 V]$ & & blanco \\
\hline$[86 r]$ & $\begin{array}{l}\text { Confessionario breve en } \\
\text { la lengua allentiac }\end{array}$ & Portada interna \\
\hline$[86 v]$ & $\begin{array}{l}\text { Decreto de la Audiencia de Lima } \\
\text { Licencia de Esteban Páez }\end{array}$ & Repetido \\
\hline$[87 r]-[92 v]$ & Confessionario allentiac & \\
\hline$[93 r]$ & $\begin{array}{l}\text { Arte y gramática breve de } \\
\text { la lengua allentiac }\end{array}$ & Portada interna \\
\hline$[93 \mathrm{~V}]$ & $\begin{array}{l}\text { Decreto de la Audiencia de Lima } \\
\text { Licencia de Esteban Páez }\end{array}$ & Repetido \\
\hline$[94 \mathrm{r}]-[106 \mathrm{~V}]$ & Arte de la lengua allentiac & \\
\hline$[106 \mathrm{~V}]$ & "Colofón” & Nota final del arte, para ambas lenguas \\
\hline$[107 r]$ & Tabla del arte allentiac & \\
\hline$[107 \mathrm{~V}]-[108 \mathrm{~V}]$ & & blanco \\
\hline$[109 r]$ & Vocabulario breve en lengua allentiac & Portada interna \\
\hline$[109 v]$ & $\begin{array}{l}\text { Decreto de la Audiencia de Lima } \\
\text { Licencia de Esteban Páez }\end{array}$ & Repetido \\
\hline [110r]-[118r] & Vocabulario breve en lengua allentiac & \\
\hline [118v-120r] & & blanco \\
\hline
\end{tabular}

\subsubsection{Los paratextos generales}

Abre el trabajo una portada principal que cumple con los imperativos legales que se habían establecido a mediados del siglo XVI (Marsá Vilá, 2001). Por lo tanto, además del título, con- 
tiene los datos completos de la edición: que la obra fue aprobada por fray Juan Pérez de Espinosa; que su autor, Luis de Valdivia, pertenecía a la Provincia jesuítica de Perú; que cuenta con Licencia; que fue impresa por Francisco del Canto en Lima, en 1607. Posee también un escudete de la Compañía.

Posteriormente, encontramos un aparato paratextual de tipo legal para los dos tratados, incorporado como consecuencia del proceso obligatorio de censura ${ }^{13}$. En el "Decreto de la Audiencia” se da la licencia de impresión y el privilegio (diez años); en este texto, por lo tanto, confluyen dos asuntos de interés editorial: el ideológico y el comercial (cfr. Reyes, 2000). En la licencia del Padre Provincial, Esteban Páez, se autoriza la impresión, "por particular comisión que para ello tengo del muy R. P. Claudio Aqua Viva, nuestro Preposito General”. El texto de fray Iván Pérez de Espinosa, Obispo de Santiago de Chile, también contiene la autorización, motivada por la necesidad de evangelizar a los huarpes, que "padecen de enseñanza"; asimismo, ordena que los doctrineros tengan la obra, pues se espera copiosos frutos de ella. Los tres documentos se otorgaron tras la revisión de expertos, cuya opinión se expone en las aprobaciones del licenciado Melchor de Urbina y de Ciriaco Vello de Zárate; ambos firman como personas nacidas y criadas en Cuyo, conocedores del millcayac y allentiac, que juzgan positivamente la traducción y valoran la obra como un servicio a Dios.

También se insertan paratextos inspirados en la tradición de la escritura impresa. Hallamos, así, la dedicatoria del autor al Obispo de Santiago de Chile, Ivan Pérez de Espinosa. En ella Valdivia (1607) le ruega recibir la obra que ofrenda, recurriendo al tópico de empequeñecer su trabajo; también expone que escribió el volumen durante los años que estuvo en Chile y que le parece conforme al celo que el obispo tiene de las almas de Cuyo. Informa que le había presentado la obra en Chile y que el mismo Pérez la aprobó, previo examen. Posteriormente, se incluye un texto titulado "Al lector", que cumple la función de proemio, donde se da noticia sobre lenguas de Cuyo, entre las cuales las generales son el millcayac, "que corre delde la Ciudad de Mendoça valle de Huentata hazta el Sur, de la qual poco o nada le diferencia la lengua Puelche y los demas Indios que ay delde alli hasta enfrente de la Ciudad de la Villarica y Valdiuia la entienden", y el allentiac, "que corre delde la Ciudad de fant Iuan de la Frontera hazia el Norte, la qual entienden los mas de los Indios que ay halta enfrente de la Ciudad de Coquimbo" ([8r]). Llama la atención que Valdivia haga referencia a la variedad dialectal de Cuyo como motivo para describir estos dos idiomas (y no otros). Lo anterior, sumado al interés del obispo sobre aquella provincia (según la dedicatoria), nos lleva a pensar que, aunque el autor conoció a sus informantes en Santiago, el volumen de 1607 se dirigía a los religiosos que misionarían en Cuyo.

13 A partir de la Pragmática de 1558, las licencias de virrey y arzobispo se debían insertar en el volumen junto con aprobaciones y correcciones de censores e inquisidores (Bègue, 2009). 
Al igual que había hecho para alentar el aprendizaje del mapudungun, Valdivia (1067: [8r]) expone las razones que "facilitan y animan mucho el aprender estas lenguas". Encuentra, en este caso, cinco: (1) son lenguas generales ${ }^{14}$; (2) sus hablantes son indios de paz, que sirven a los cristianos por falta de obreros desde hace 50 años, pese a lo cual son los más necesitados del reino y son infieles; (3) estos idiomas no tienen dificultad en la pronunciación; (4) las dificultades de la conjugación se facilitan con las reglas del arte, pues casi nueve conjugaciones se reducen a una, y porque las transiciones son fáciles; (5) los vocablos suficientes para las tareas misioneras están contenidos en los vocabularios y su aprendizaje será simple para quien conoce la lengua de Chile (mapudungun) o de Cuzco (quechua).

Tras el arte allentiac, aparece una nota que cierra dicho componente:

No penfaua imprimir eftos dos Artes de lengua Millcayac y Allentiac por auer mas de ocho años que los hize, y otros tantos que no ufo estas dos lenguas efperanso hasta tener mas ufo y exercicio dellas, pero confiderando la gran nefcesidad de eftos indios pa[re]cio mas gloria de nuestro feñor imprimillos junto con los Catecifmos para aya algun principio aunque imperfeeto, y el tiempo lo perficionara (Valdivia, 1607: [106v]).

Aunque podría asemejarse a un “colofón”, creemos que más bien es una especie de paratexto de responsabilidad del autor. Con este breve texto, parece completar una información que quedó pendiente en el proemio, respecto de las dos lenguas indígenas que incorpora en su volumen.

\subsubsection{El tratado millcayac}

Este tratado está compuesto, como hemos dicho, por obras catequéticas y lingüísticas; ocupa desde el folio [9r] al [72r]. Encontramos, primero un título que anuncia la doctrina cristiana y el catecismo, pero el primer apartado de la obra contiene solo la doctrina, compuesta por: "persignar", "Padre Nuestro", "Ave María”, "Credo", "Salve”, "Los mandamientos de la Ley de Dios", "Los mandamientos de la Santa Madre Iglesia”, "Los sacramentos", "Las obras de misericordia”, "Virtudes teologales", "Virtudes cardinales", "Enemigos del alma”, "Pecados capitales", "Los novísimos" y "Confesión general”. A todos los textos, en español, les sigue inmediatamente abajo la traducción millcayac. Los contenidos de esta doctrina son similares al modelo de los textos conciliares (1584) que el autor ha seguido, pues, recordemos, aquellas obras debían traducirse a los idiomas de la arquidiócesis limense. Las únicas diferencias son una alteración en el orden entre "Pecados capitales" y “Enemigos del alma”, y la ausencia de los catorce artículos de la fe que aparecen en el complemento pastoral.

14 La consideración de una lengua como general también representa un interés relacionado con las políticas de la evangelización, pues estas se preferían para la cristianización (cfr. Ridruejo, 2007). 
Posteriormente, se halla el "Breve catecismo", con 49 preguntas concisas en español, numeradas, con sus correspondientes respuestas. Les sigue la traducción respectiva al miIlcayac. Pese a su “brevedad”, es más extenso que su homólogo limense de 1584, que solo contiene 15 preguntas y respuestas, y que el Arte mapudungun, con 17 preguntas-respuestas. Lo anterior se debe a que en este, millcayac, se han agregado interrogantes que en el complemento pastoral están contenidas en el "Catecismo mayor", "para los que son más capaces" (Concilio Provincial de Lima, 1584: 25r). Al igual que aquella edición, y en concordancia con la tradición del tipo textual, presenta una estructura dialógica que, como recurso didáctico, imita los diálogos alumno-maestro.

Se encuentra un "Acto de contricion" en español y millcayac, también presente en el Arte de 1606, aunque allí aparece solo en mapudungun. El alocutario de este texto es el indígena, que se dirige a Dios, entendido no ya como un aprendiz de la fe, sino como cristiano que dialoga con la divinidad. Se sugiere que el neófito reconozca a Dios, exponga sus pecados, se arrepienta y suplique perdón.

El "Confessionario breve en la lengva millcayac" presenta una portada interna, que contiene los datos completos de la impresión y un escudete jesuita. Asimismo, repite el Decreto de la Audiencia de Los Reyes. Tras cada uno de sus subapartados en español se ofrece la traducción al millcayac. Contiene “Antes de la confession” “ “Exortacion”, en la cual se incorpora una oración que el indígena deberá dirigir a Dios. Con lo anterior, la obra se acerca más al confesionario de los complementos pastorales de 1585(a) que al confesionario mapudungun de Valdivia (1606), donde encontramos primero el texto en la lengua de los mapuches y tras él la versión en español. Le siguen las preguntas ordenadas según el apego a los mandamientos, igual como en el confesionario limense (1585a) y en Valdivia (1606). De alguna forma, podemos ver la línea de continuidad entre las obras, por el motivo evidente de que el complemento pastoral sirvió como un modelo que se tradujo y se adecuó.

Posteriormente incluye un apartado "Para acabar la confeslion", en el cual se inquiere sobre los pecados cometidos y se dan recomendaciones sobre la oración, el arrepentimiento y la determinación de no volver a pecar. Asimismo, hallamos "La exortacion antes de absoluer". Posteriormente, se leen algunas instrucciones: "Dele la penitencia diciendo..." y "Acomode la penitencia a la capacidad del indio...". Por último, se ofrece la "Absolvcion” (en latín) y se dan las últimas recomendaciones a los misioneros, adivirtiéndoles los riesgos de la confesión, con especial preocupación por el sexto mandamiento, relacionado con las prácticas sexuales: "No le enfeñe (por ventura preguntando) los peccados que no labia” (Valdivia, 1607: [36r]).

Después de los textos catequéticos hay dos de carácter lingüístico: arte y vocabulario. Tras una portada interna que se refiere a la obra completa, el decreto de la Audiencia y la licencia del Padre Provincial, se ofrece el "Arte de la lengva millcayac". Está compuesto por veinte capítulos. El I trata sobre el nombre y destaca por el apego a la gramática latina: "El 
nombre en efta lengua no tiene mas de vna terminacion en todos los calos, y por las particulas que fe pondran en el Exemplo fe diftinguen los calos y numeros" (Valdivia, 1607: [38r]). El ejemplo, por cierto, es el mismo que ha empleado en el Arte de 1606: "Padre", Prri.

Valdivia (1607: [38v]) indica que "Ios Subftantiuos carecen de generos"; al resaltar esta diferencia deja ver que, quizás de modo inconsciente, está buscando en la lengua descrita lo que posee la propia (español) y aquella cuya tradición de descripción gramatical conoce (latín). Por este motivo, necesita destacar que sí hay marcas que indican "sexo masculino y femenino", los que se distinguen "añadiendo elta palabra (yam) que lignifica el fexo mafculino, o efta palabra (axey) que lignifica el fexo femenino como (ñochum yam) varon (ñochum awey) muger" ([38r]]). El capítulo II está dedicado al pronombre; en él se ofrece una relación de los pronombres primitivos y se indica que han de declinarse como el nombre, a excepción del plural y algunos genitivos. Más adelante se estudian los pronombres posesivos, cuya función cumplen los genitivos de los pronombres primitivos.

Los capítulos III al XII tratan sobre el verbo. Para Ridruejo (2009) es la parte central del arte millcayac (tal como ocurría en el Arte de 1606)15. La descripción del verbo es bastante sistemática y su complejidad ha obligado a Valdivia (1607) a buscar soluciones novedosas, aunque también acude a la tradición de la gramática latina y a la del mapudungun, que ya había descrito (Ridruejo, 2009). En el capítulo III da la información básica sobre la morfología del verbo "en común", de la cual "fe formā las demas terminaciones de los demas tiempos y modos" (Valdivia, 1607: [40r]).

El autor identifica los cinco modos de la gramática latina: indicativo, imperativo, optativo, subjuntivo e infinitivo. Cada modo posee tiempos; cada tiempo de los cuatro primeros modos posee persona (primera/segunda/tercera) y número (singular/plural). Explica que existe una diferencia entre verbos en los que (no) pasa la acción de una persona a otra, voz activa y voz pasiva, verbos con partículas especiales para afirmación y negación. Son estas características las que lo ayudan a estructurar los capítulos siguientes: voz activa cuando no pasa la acción de una persona a otra (IV), ordenado de acuerdo a modos y tiempos; formación de dichos tiempos y personas en general (V); variaciones en la formación de dichos tiempos y personas (VI); práctica de las reglas dadas en el capítulo VI (VII); verbo ser en voz pasiva (VIII); verbo negativo e interrogativo (IX); verbo transitivo (X); partículas que modifican el significado de los verbos (XI); participios y otros casos, como acusativo en verbo activo y verbos de movimiento (junto con algunos nombres) (XII).

15 Ridruejo (2009) es la descripción más detallada sobre este asunto. También Zwartjes (2000) lo ha estudiado, aunque en su investigación el millcayac constituye una de las lenguas descritas, junto con el mapudungun y el guaraní. Díaz-Fernández (2014) lo aborda en relación con el verbo mapuche y allentiac. 
En el capítulo XIII, Valdivia (1607) se detiene sobre los relativos, para cuyo uso reconoce tres formas: participios, pronombre epi, relativos de lugar acheta y epta. Posteriormente, en el XIV se refiere a los nombres comparativos y superlativos. Los nombres numerales (cardinales y ordinales) y nombres de unidades de medida se recogen en el capítulo XV. Finalmente, los nombres de tiempos, edades y parentescos aparecen en el capítulo XVI. También se estudian otras categorías morfológicas: adverbios (XVII), preposiciones (XVIII), conjunciones e interjecciones (XIX). El último capítulo versa sobre el acento (XX). Se incorpora una clausio, "AD MAIOREM DEI GLORIAM", que corresponde al lema jesuítico, y una tabla de los capítulos del arte.

Otra portada interna nos indica el inicio del "Vocabvlario breve en lengva millcayac", el cual está precedido del decreto de la Audiencia y de la Licencia del Padre Provincial, y se ordena en dos columnas. Se ciñe a la tradición y está ordenado alfabéticamente; ofrece la entrada en la lengua indígena y su equivalente en español.

En concordancia con las informaciones del arte sobre los verbos, se incorporan las diferencias entre verbos reflexivos y transitivos: "Elpātarle. Lemtequina. Elpantar a otro. Lemtec", "Rezucitar. Laguimul- tequina. Rezucitar a otro. Laguy Muel.hereyna” (Valdivia, 1607: [70v]). En el afán del jesuita por ofrecer a los misioneros aquellas informaciones propias de la cultura indígena, ofrece conceptos que no están presentes en el español, para lo cual opta por incluir frases que no tienen equivalente en español, como "Alcançar lo que esta en alto EpitaEtu gualte" ([62v]).

Por otra parte, la ausencia de una etnohistoria huarpe dificulta la comprensión de la fidelidad de la interpretación del religioso sobre términos religiosos. Por ejemplo, "Bautizar Henetoguina” ([63r] ) significaría, de acuerdo con la obra del jesuita, 'poner nombre’. Hemos de suponer que se trata de una acomodación de términos indígenas para explicar un sacramento cristiano, producto de las necesidades de la evangelización. Con conceptos no religiosos también busca aproximaciones, como en "Abogado. Xamtigue" ([62r]), cuyo significado, según el Arte, es 'el que habla'. La incorporación de este término está también motivada por la evangelización; de hecho, se ha usado antes en el "Salve" de la Doctrina:

- Español: "pues abogada nuestra buelue a nolotros elfos tus ojos milericordiolos" (Valdivia, 1607: [10v]).

- Millcayac: "Eguy tamari cuchu tamari xamtigue cach ñuhu teEtigue neu xeguerchep cuchu zich” (Valdivia, 1607: [10v]).

Posteriormente, se indica "Fin del Vocabulario Millcayac" y se ofrece la clausio "AD MARIOREM GLORIAM DEI”, similar a la del Arte, aunque con una leve modificación sintáctica. Estas disposiciones son sistemáticas a lo largo de la obra, lo que demuestra el cuidado de la impresión. 


\subsubsection{El tratado allentiac}

La estructura de este tratado, que va desde el folio [73r] al [118r], es, básicamente, la misma que la del millcayac, por lo que Ridruejo (2009: 140) considera que se trata de artes "gemelas". Se diferencian por la mayor extensión millcayac, debido fundamentalmente a la cantidad de capítulos sobre el verbo.

Este tratado se inicia con una portada interna: "Doctrina christiana y cathecismo en la lengua Allentiac", a la cual le sigue la copia del Decreto del Real Acuerdo de los paratextos generales. Aparece, a continuación, la "Doctrina christiana en lengua allentiac", que tiene los mismos elementos que su par millcayac y que la doctrina conciliar (1584), salvo por el orden de los apartados "novísimos" y "pecados capitales". Todos los textos en español tienen, inmediatamente, la traducción allentiac.

El "Cathecismo brebe" es un poco más extenso que el millcayac (49 preguntas), pues contiene 60 preguntas y respuestas, con la traducción allentiac. En ambos casos, el autor ha buscado una solución intermedia entre el catecismo breve y el catecismo mayor de los complementos pastorales (1584).

Los contenidos de los catecismos millcayac y allentiac (Valdivia, 1607) son similares, pero la mayor extensión del segundo se debe, entre otras razones, al desarrollo más detallado de una pregunta; así, el catecismo millcayac dice: "17. Adonde van las almas quando falen del cuerpo R. Si lon buenas van al Cielo con Dios, y li lon malos al infierno con el demonio" ([15V]), mientras que en el catecismo allentiac se expresa lo anterior en tres preguntas: "14. Son todos los hombres mortales. R. Si. Pero lolo el cuerpo muere el anima no muere", "15. Donde van las animas de los buenos? R. Al cielo van a la cala de Dios a eternos gozos" y "16. Y las animas de los malos adonde van? R. Al infierno a ler quemados para liempre" ([80v]). Por otra parte, en el catecismo allentiac el tratamiento de la concepción, vida, muerte y resurrección de Cristo es más minuciosa (preguntas 26 a 45 [catecismo millcayac: 25 a 35]); se incorpora el "pecado original” y se desarrolla el "bautismo".

Después se encuentra la portada interna del "Confessionario breve en la lengua allentiac", en cuyo vuelto se repiten el Decreto del Real Acuerdo y la Licencia del Padre Provincial. Está formado por: "Antes de la confession”, preguntas ordenadas según los mandamientos y "Exortacion", todos en español y allentiac. Sus contenidos son ligeramente distintos a los del confesionario millcayac:

Exhortación millcayac:

- Hijo mio el peccado es muy malo y mata al alma poniendola negra y fea por lo qual la aborrece Dios, y fe enoja mucho con ella. $\mid$ Por effo llora mucho tus peccado. Si ora no te huuieras confeffado, te fueras al Infierno por eftos peccados a fer quemado para fiempre. Y por auerte 
cōfeffado ahora todos tus peccados fin dexar ninguno, llorando de coraçon por ellos, y proponiendo la enmienda por esto Dios te quita todos tus peccados, y aora feras hijo de Dios, y yras al cielo; a donde para fiempre eftaras contento viendo a Dios Y esto que te acauo d dezir , el mifmo Iefu Chrifto hijo de Dios lo dixo.

I Dile pues hijo ahora a Dios. Dios mio con todo mi coraçon te amo, eres grā feñor hazedor mio, y que por mi remedio baxafte a hazerte hombre, y morifte en la Cruz por mis peccados. Yo he fido muy gran peccador contra ti, mucho dolor tengo en mi coraçon de mis peccados, ten tu mifericordia de mi, oluida mis pecados, entierralos, y dame tu gracia, que con ella tornare otra vez a peccar, y la penitencia q me mandare hazer el Padre por mis peccados la cüplire toda. (Valdivia 1607: [34r-34V]).

Exhortación allentiac:

I Hijo mia eftos peccados que agora me has dicho, fon muy malos, y con ellos has offendido mucho a Dios. Dios es muy bueno, y por effo aborrece todo lo que es malo.

$\checkmark$ Para que quite estos peccados has de llorar en tu coraçon diziendo.

I Dios mio, Criador mio, que embiafte tu hijo para que fe hizieffe hōbre por mi, y murieffe en la Cruz por mis peccados para librarme dellos. Mucho me pefa de auer peccado. Mucho temo el yr al Infierno por mis peccados. Ten mifericordia de mi peccador, quitame los pecados, perdonamelos, oluidalos, entierralos. Ya Señor no peccare mas. Dame tu gracia para no peccar mas, Y la penitencia que el Padre mi dixere que haga yo la complire de veras.

(Valdivia, 1607: [92r]).

Valdivia (1607) ofrece, así, diversas soluciones discursivas a los misioneros en un solo volumen, pues, aunque las traduce a lenguas distintas, usa el español como código para la comunicación con el lector. Por otra parte, mientras en millcayac había un aparato de cierre de confesión, en el tratado allentiac se reduce a: "Tienes mas peccados de los que me as dicho?" ([92r]). Por ello, sostenemos que este confesionario se pensó para circular en un volumen que contuviera, además, su par millcayac, que tenía instrucciones más detalladas sobre la administración del sacramento. De hecho, en aquel se incorporaba una exhortación al inicio de la confesión que no aparece en allentiac.

Por otra parte, las primeras nueve preguntas del primer mandamiento muestran la adecuación a la visión de mundo huarpe, a partir de los contenidos del texto limense (1585a) y del confesionario de 1606. Tomemos como ejemplo las preguntas número 6 y 7 :

- Complemento pastoral: 6. Has offrecido a los muertos alguna cola? / 7. Has delenterrado y hurtado de la Yglelia algun defüto para lleuarlo a la huaca o a otra parte? (7r).

- Confesionario mapuche: 6. Has ofrecido a los muerto algun mayz o chicha pēfando que vienen a comer y beuer?/ 7. Has delenterrado y hurtado de la Yglelia algun defūto para enterrallo junto a tu cala como tus atepallados lo hazian? (5v). 
- Confesionario millcayac: 6. Enterrado algun difunto polifte en fu fepultura mayz, o chicha, o jo*as, tortolas, mates, penfando que los comera? / 7. Muriendolete tu padre? Marido? 0 hijo? fueles hazer lo que hazen los que no lon chriftianos? Eltarte dançando, o bebiendo chicha, o eltarte lin labar la cara, o otra cola destas? ([24V]).

- Confesionario allentiac: no contiene la información.

En la pregunta 6, sobre la base general "ofrecer algo a los muertos", Valdivia explicita los elementos que ha recogido de las prácticas de los mapuches (1606) y de los huarpes-millcayac (1607); es probable que no haya conocido estos usos entre los huarpes-allentiac, pues no los ofrece. En la pregunta 7, el complemento pastoral (1585a) informa sobre el hurto de cadáveres y su entierro en huacas ('Iugares sagrados' incas); Valdivia (1606) se refiere a la práctica mapuche de sepultar los cadáveres junto a la vivienda, mientras que, para los huarpes millcayac y allentiac (en 1607) omite esta información, pues probablemente no la oyó de sus informantes, quienes, trasladados de su lugar de origen, difícilmente podían tener una práctica vinculada con un lugar culturalmente significativo. No obstante, para los millcayac introduce otras prácticas relacionadas con el rito funerario que sí recogió.

Un elemento a destacar en este texto allentiac es la nota etnográfica que aparece tras la traducción al allentiac del primer mandamiento: "Hunuc huar es un falfo numen a quien adoran que ellos aprehenden està en la Cordillera nebada, al qual repeEtan, Ilaman y temen" (Valdivia, 1607: [88r]). En esta se observa el esfuerzo del jesuita por dotar a los misioneros de herramientas suficientes para conocer la cultura huarpe y así sustentar la evangelización. Ahora bien, también vemos en ella los prejuicios impuestos por su visión de mundo, ya que el autor no solo considera "falsa” la creencia huarpe, sino que, además, en su afán por hacer de esta cultura un objeto de evangelización, intenta equiparar su práctica con el cristianismo, que "respeta, llama y teme" a su divinidad.

Después de las obras catequéticas están las lingüísticas. Así, hallamos la portada de “Arte y gramatica brebe de la lengva allentiac", con datos de impresión y escudete jesuita, seguida, al vuelto, del Decreto del Real Acuerdo y la Licencia del Padre Provincial. El arte está compuesto por doce capítulos. El primero trata nombres sustantivos y adjetivos, también con apego a la gramática latina, por lo que se asemeja a la descripción millcayac (accidentes de número y caso). Recurre al ejemplo "Padre”, también empleado con el mapudungun y el millcayac. Sobre el adjetivo, entrega nociones sintácticas; señala que carece de género e informa la construcción de la significación de "sexo masculino" o "sexo femenino". En el capítulo II, el autor aborda el pronombre; sigue la estructura que ha presentado en el arte millcayac: ofrece una relación de los primitivos e indica que se declinan como el nombre, excepto el genitivo de singular y el plural, igualmente refiere los pronombres posesivos.

Entre los capítulos III y VII está el estudio del verbo. Como hemos referido, se diferencia del arte millcayac, pues en aquella el tratamiento del verbo es mucho más extenso (capítulos 
III-XII), debido a que "la morfología verbal era más compleja en millcayac que en allentiac" (Ridruejo, 2009: 140).

La presentación se ofrece desde la base de la morfología verbal allentiac en voz activa y pasiva (III) hasta aquellas nociones que la complementan (IV). No obstante, el tratamiento del verbo no termina aquí: el capítulo V aborda "el verbo interrogatiuo, y negatiuo" (Valdivia, 1607: [100v]) tanto en sus formas generales como en sus excepciones; el capítulo VI trata sobre las transiciones afirmativas y negativas, mientras que el capítulo VII se refiere a la construcción del nombre participio y verbo. En este punto, Valdivia (1607: [103r]) remite al arte millcayac: "concuerdan el nombre y verbo en numero y perfona como en la lengua Millcayac, cuyas reglas firuen tambien a efta”. Con esto, el criterio de la independencia de las artes disminuye, así como la posibilidad de que se hayan impreso por separado debido a que sus públicos serían diferentes. Este hecho, al igual que el confesionario, indica que el autor pensaba más bien en lectores del volumen completo (cfr. § 4), los cuales, por cierto, en su horizonte de escritura eran lo suficientemente competentes para, al menos, interesarse en ambas lenguas, abogando por un ideal misionero jesuita. Tangencialmente, en el capítulo XI se retoma el verbo: "de las particvlas, que juntas a los verbos hazen variedad en fi fignificacion” ([105V]). Trata aquí sobre partículas con diversos valores, como hay ('actualidad' de la acción), ychacta ('reciprocidad'), lau ('iteración de la acción') y petia ('poder hacer la acción’).

El capítulo VIII estudia la composición de relativos y comparativos, y los numerales cardinales y ordinales; a propósito de los últimos, Valdivia (1607) nos envía una vez más al arte millcayac: "Concuerda en muchas colas efta lengua en los numeros con la Millcayac veafe el Capitulo Quinze del arte Millcayac" ([104r]). El capítulo IX aborda los adverbios, que tienen "todos los generos que en otras lenguas" ([104r]); el X, las preposiciones, conjunciones e interjecciones; y, por último, el XII incluye las reglas de acentuación de nombres y verbos.

Al igual como ocurría en el arte millcayac, aparece una clausio "AD MAIOREM DEI GLORIAM". A continuación, antes de la tabla con los capítulos del arte, está el "colofón" que hemos referido (cfr. § 5.1.1). Tras él, hay un "FINIS" (que puede considerarse como una segunda clausio).

Una nueva portada interna introduce el "Vocabvlario breve en lengua allentiac”, seguido por el Decreto del Real Acuerdo y por la Licencia del Padre Provincial. Valdivia (1607) presenta el vocabulario por orden alfabético, con las entradas en español; con ello, introduce una novedad respecto de sus léxicos mapudungun y millcayac, que tenían la entrada en lengua indígena.

En la traducción de términos religiosos, la solución es similar a la del vocabulario millcayac. Así, "bautizarse” se traduce como hentamnen < hene, 'nombre'; taunen, 'poner', que también suponemos un producto forzado por los objetivos evangélicos. En este sentido, para Canals Frau (1941: 46), "el propósito principal de los afanes lingüísticos del P. Valdivia al componer su obra sobre el Allentiac era el de catequizar a los indios de Cuyo. Es esto un aspecto 
del asunto al que pertenece el mayor interés, puesto que limita grandemente el vocabulario de esta lengua que se da a conocer, y porque además, gran parte de lo que se trae en léxico tiene un sentido abstracto y artificial dentro del conjunto de la mentalidad primitiva de los Huarpes". Continuando con la estructura del volumen, se cierra con "Fin del Vocabulario Allentiac" (Valdivia, 1607: [118r]) y se repite, con una ligera alteración sintáctica, la clausio "AD MAIOREM GLORIAM DEI", tal como sucedía en el tratado millcayac.

\section{Consideraciones finales}

El volumen millcayac y allentiac que descansa en la Biblioteca Casanatense posee un valor patrimonial especial: constituye el único ejemplar completo de la tirada que salió en 1607 de las prensas de Francisco del Canto, en Lima, cuyo autor es el jesuita Luis de Valdivia. Pertenece a la tradición de la lingüística misionera americana, en relación particularmente con los complementos pastorales (1584 y 1585a) del III Concilio Limense, que estableció un modelo (obligatorio) para los misioneros de la arquidiócesis. Fue este el que Luis de Valdivia siguió en sus obras de 1606 y 1607, de modo que ambos trabajos se asemejan. En definitiva, forman parte del mismo proyecto evangélico del jesuita granadino. Junto con Sermón en lengua de Chile (1621), forman una obra misionera de inmensas proporciones.

En este trabajo, en su apartado $\$ 5$, hemos querido explorar algunas de las posibilidades de análisis comparativo entre los tratados millcayac y allentiac, el Arte mapudungun de 1606 y los complementos pastorales (1584 y 1585a). Ahora bien, este es solo un primer acercamiento, pues sobre este asunto los investigadores deberán dilucidar varios aspectos, como la ausencia en el volumen de $\mathbf{1 6 0 7}$ de las coplas en mapudungun y del silabario que aparecen en la obra de 1606. Otro posible objeto de investigación es la traducción de los términos cristianos, pues vemos aquí dos soluciones: por un lado, Valdivia (1607) mantuvo los nombres en español para las deidades de su religión e identificó las nociones huarpes, estableciendo, así, claramente los límites de las creencias, al igual como había hecho con el mapudungun; por otro lado, y como reconoce Zapater (1992: 74), "une vocablos huarpes con voces españolas”, como "Dios Padre" > Dios Piata, allen. ( [75r]), con lo que acentúa el hibridismo cultural.

Sobre la dependencia de los dos tratados que forman el volumen de 1607, creemos que esta es parcial. Aunque la circulación de cada uno de manera separada podría facilitar la catequesis y el aprendizaje de la lengua respectiva, ambos se complementan. Este hecho se debe, en primer lugar, a la estructura del confesionario allentiac respecto del confesionario millcayac; en segundo lugar, a las referencias anafóricas en el arte allentiac, que conducen al primer arte del volumen (millcayac).

Por otra parte, a juzgar por la relevancia que parecen haber tenido el millcayac y el allentiac en la vida santiaguina, los contactos interétnicos del Chile colonial podrían describirse 
como propios de una diversidad de la cual la historia parece no haberse hecho cargo: no solo españoles y mapuches vivían en Santiago, sino también estos indígenas "trasladados", junto con cunzos, negros... En efecto, la historia de este contacto es uno de los capítulos cuya escritura está pendiente en la historia de Chile y la consideramos como un importante apartado para la descripción de la sociolingüística histórica chilena.

La escasez de estudios sobre el millcayac y el allentiac, sin duda, se ve motivada porque se trata de lenguas extintas y, también, según Ridruejo (2009: 137), por la "extraordinaria rareza" de los ejemplares conocidos hasta ahora. Esperamos que, con esta noticia bibliográfica, los estudiosos de la lengua se interesen por estos idiomas y por su proceso de extinción, paradigma de aquel que hoy afecta a muchas lenguas de América. En la actualidad, nos encontramos gestionando, con el apoyo de la Dirección General de Bibliotecas de la Universidad Nacional Autónoma de México, una copia digital con la Biblioteca Casanatense de Roma. Desde ahora nuestro agradecimiento a ambas instituciones. Nuestro objetivo es realizar una edición de esta obra, de modo de acercarla a la comunidad científica y al público general interesado por estas lenguas. Consideramos que contar con un facsímil es un imperativo para acercar este patrimonio bibliográfico americano a los lectores.

\section{Bibliografía citada}

\subsection{Fuentes}

Concilio Provincial de Lima, 1584: Doctrina christiana, y catecismo para instrvccion de los Indios, y de las demas perfonas, que han de fer enfeñadas en nueftra fanEta Fé. Con vn confessionario, y otras cosas neceffarias para los que doetrinan, que fe contieuen en la pagina figuiente, Ciudad de los Reyes: Antonio Ricardo.

Concilio Provincial de Lima, 1585a: Confessionario para los curas de indios. Con la Instrvcion contra svs Ritos: y Exhortacion para ayudar al buen morir: y fumma de fus priuilegios: y forma de Impedimentos del Matrimonio. Compvesto y tradvzido en las Lenguas Quichua, y Aymara, Ciudad de los Reyes: Antonio Ricardo.

Concilio Provincial de Lima, 1585b: Tercero Cathecismo y exposicion de la DoEtrina Christiana, por Sermones. Para que los cvras y otros miniftros prediquen y enfeñen a los Yndios y a las demás perfonas, Cuidad de los Reyes: Antonio Ricardo.

VALDIVIA, Luis de, 1606: Arte, y gramatica general de la lengva que corre en todo el Reyno de Chile, con vn Vocabulario, y Confelfionario. Compueltos por el Padre Luys de Valdivia, de la Compañía de Jelus, en la Prouincia del Piru. Ivntamente con la Doctrina Chris/tiana y Cathecilmo del Concilio de Lima en Elpañol, y dos traducciones del en la lengua de Chile, que examinaron y aprobaron los dos Reverendifsimos feñores de Chile, cada qual la de lu Obifpado, Lima: Francisco del Canto. 
ValdiviA, Luis de, 1607: Doctrina christiana, cathecismo y confessonario en las dos lenguas más generales que corren en la Provincia de Cuyo, juridicion del Reyno de Chile, Lima: Francisco del Canto.

VALDIVIA, Luis de, 1894 [1607]: Doctrina cristiana y catecismo con un confesionario, arte y vocabulario breves en la lengua allentiac por el Padre Luis de Valdivia de la Compañía de Jesús. Reimpreso á plana y renglón, con una reseña de la vida y obras del autor, José Toribio Medina (ed.), Sevilla: E. Rasco.

VALDIVIA, Luis de, 1913 [1607]: Doctrina Christiana y Confessionario Breve en la lengua millcayac, Rudolph R. Schller (ed.) en "Discovery of a fragment of the printed copy of the work on the miIlcayac language by Luis de Valdivia, with a bibliographical notice". Papers. Peabody Museum of American Archaeology an Ethnology III/5, 220-258.

ValdiviA, Luis de, 1918 [1607]: Fragmentos de la Doctrina Cristiana en la lengua Millcayac del P. Luis de Valdivia únicos que hasta ahora se conozcan sacados de la edición de Lima de 1607 y reimpresos en facsimil con un prólogo, José Toribio Medina (ed.), Santiago de Chile: Imprenta Elzeviriana.

VALDIVIA, Luis de, 1943 [1607]: Arte y gramática en dos lengvas de indios Millcayac y Allentiac de las Ciudades de Mendoça y S. I uan de la Frontera de la prouincia de Cuyo, Fernando Márquez Miranda (ed.), en "Los textos millcayac del P. Luis de Valdivia. (Con un vocabulario españolallentiac-millcayac)". Revista del Museo de La Plata, Nueva Serie, Antropología, II/12: 187-223.

Valdivia, Luis de, 1621: Sermon en lengva de Chile, de los mysterios de nvestra santa fe catholica, para dedicarla a los indios infieles del reyno de Chile, dividido en nveve partes pequeñas, acomodadas a fucapacidad, Valladolid: [Jeronimo de Murillo].

\subsection{Estudios}

AdelaAr, Willem F. H., 2004: The languages of the Andes, Cambridge: Cambridge University Press.

Aıello, Rita, 2005: "Il fondo incunabli e rari” en Angela Cavarra, Biblioteca Casanatense. Roma. Guida breve, Roma: Ministero per i Beni e le Attività Culturalli, Dipartamento per i Beni Archivistici e Librari, Direzione Generale per i Beni Librari e gli Istituti Culturali/Nardini, 22-25.

BĖGUe, Alain, 2009: "De leyes y poetas. La poesía de entre siglos a la luz de las aprobaciones (siglos XVII-XVIII)", en M. Arredondo, P. Civil y M. Moner (comps.): Paratextos en la literatura española. Siglos XV-XVIII, Madrid: Casa de Velázquez, 91-107. 
Canals Frau, Salvador, 1940: "Doctrina cristiana y catecismo en la lengua allentiac, que corre en la ciudad de San Juan de la Frontera, con un confesionario, arte y vocabulario breves por el P. Luis de Valdivia, S. J.", Anales del Instituto de Etnografía Americana I, 19-94.

Canals Frau, Salvador, 1941: "La lengua de los huarpes de San Juan”, Anales del Instituto de Etnografía Americana II, 43-167.

Canals Frau, Salvador, 1942a: "La cultura de los huarpes", Anales del Instituto de Etnografía Americana III, 289-322.

Canals Frau, Salvador, 1942b: "La lengua de los huarpes de Mendoza", Anales del Instituto de Etnografía Americana III: 157-184.

Canals Frau, Salvador, 1973: Poblaciones indígenas de la Argentina, Buenos Aires: Sudamericana.

Cancino Cabello, Nataly, 2015: "El "Tercero Catecismo" del III Concilio de Lima: un modelo textual para la evangelización americana” en José María GARCíA MARTín (dir.): Actas del IX Congreso Internacional de Historia de la Lengua Española Il, Madrid: Arco/Libros, 1947-1960.

Cavarra, Angela, 2005: "Profilo storico" en Angela Cavarra, Biblioteca Casanatense. Roma. Guida breve, Roma: Ministero per i Beni e le Attività Culturalli, Dipartamento per i Beni Archivistici e Librari, Direzione Generale per i Beni Librari e gli Istituti Culturali/Nardini, 5-16.

Díaz, José Manuel, 2010: Razón de Estado y buen gobierno. La Guerra Defensiva y el imperialismo español en tiempos de Felipe III, Universidad de Sevilla.

Díaz-Fernández A., Antonio E., 2014: “Exploración tipológica de la morfología verbal en millcaayc, allentiac y mapuzungun" en Marisa Malvestittı y Patricia Dreidemie (comps): III Encuentro de Lenguas Indígenas Americanas. Libro de Actas, Universidad Nacional de Río Negro, 211-222.

Foerster G., Rolf, 1996: Jesuitas y mapuches: 1593-1767, Santiago de Chile: Universitaria.

Garcia Ahumada, Enrique, 995: "Luis de Valdivia, nuestro primer catequista”, Anuario de Historia de la Iglesia en Chile 13, 9-16.

GreEnberG, Joseph, 1987: Language in the Americas, Stanford University Press.

Guibovich Pérez, Pedro, 2000: "Libros antiguos en la Universidad del Cuzco: Ia Biblioteca de los Jesuitas”, Histórica XXIV/1, 171-181. 
Mitre, Bartolomé, 1894: Lenguas americanas. Estudio bibliográfico-lingüístico de las obras del P. Luis de Valdivia sobre el araucano y el allentiak, con un vocabulario razonado del allentiak, La Plata: Talleres de Publicaciones del Museo.

Loukotka, Čestmír, 1968: Classification of South American Indian Languages, Los Angeles: University of California.

Lozano, Pedro, 1754: Historia de la Compañía de Jesús en la Provincia del Paraguay I, Madrid: Imprenta de la Viuda de Manuel Fernández y del Supremo Consejo de la Inquisición.

Lozano, Pedro, 1755: Historia de la Compañía de Jesús en la Provincia del Paraguay II, Madrid: Imprenta de la Viuda de Manuel Fernández y del Supremo Consejo de la Inquisición.

Márquez Miranda, Fernando, 1943: "Los textos millcayac del P. Luis de Valdivia (con un vocabulario español-allentiac-millcayac)", Revista del Museo de La Plata, Nueva Serie, Antropología II/12, 187-223.

MaRSÁ VILA, María, 2001: La imprenta en los Siglos de Oro (1520-1700), Madrid: Ibérica.

Medina, José Toribio, 1878a: Historia de la Literatura colonial de Chile II, Santiago de Chile: Imprenta de la Librería Mercurio.

Medina, José Toribio, 1878b: Historia de la Literatura colonial de Chile III, Santiago: Imprenta de la Librería Mercurio.

MedinA, José Toribio, 1894a: "Advertencia” en Doctrina cristiana y catecismo con un confesionario, arte y vocabulario breves en la lengua allentiac por el Padre Luis de Valdivia de la Compañía de Jesús. Reimpreso á plana y renglón, con una reseña de la vida y obras del autor, Sevilla: E. Rasco, vii-x.

Medina, José Toribio, 1894b: "Noticia biográfica” en Doctrina cristiana y catecismo con un confesionario, arte y vocabulario breves en la lengua allentiac por el Padre Luis de Valdivia de la Compañía de Jesús. Reimpreso á plana y renglón, con una reseña de la vida y obras del autor, Sevilla: E. Rasco, 1-78.

Medina, José Toribio, 1897: "Prólogo" en Nueve sermones en lengua de Chile por el P. Luis de Valdivia de la Compañía de Jesús. Reimpresos a plana y renglón del único ejemplar conocido y precedidos de una bibliografía de la misma lengua, Santiago: Elseviriana, vii-xvi.

Medina, José Toribio, 1918a: “Carta dedicatoria del Editor a su amigo D. Samuel A. Lafone Quevedo" en Fragmentos de la Doctrina Cristiana en la lengua Millcayac del P. Luis de Valdivia 
únicos que hasta ahora se conozcan sacados de la edición de Lima de 1607 y reimpresos en facsimil con un prólogo, Santiago: Imprenta Elzeviriana, v-vii.

Medina, José Toribio, 1918b: “Noticia Bibliográfica, Histórica y Etnográfica” en Fragmentos de la Doctrina Cristiana en la lengua Millcayac del P. Luis de Valdivia únicos que hasta ahora se conozcan sacados de la edición de Lima de 1607 y reimpresos en facsimil con un prólogo, Santiago: Imprenta Elzeviriana, xx-xxxvi.

Michielı, Catalina Teresa, 1990: "Millcayac y allentiac: Ios dialectos del idioma huarpe”, Publicaciones 17, 1-40.

Michielı, Catalina Teresa, 1994: Antigua historia de Cuyo, San Juan: Ansilta.

Michiel, Catalina Teresa, 1996: La fundación de las ciudades de Cuyo (ensayo histórico), San Juan: Ansilta.

Oré, Luis Jerónimo de, 1598: Symbolo Catholico indiano, Lima: Antonio Ricardo.

Ovalle, Alonso de, 1646: Historica Relacion del Reyno de Chile y las mifiones y minifterios que exercita en la Compañia de Jesus, Roma: Francisco Caballo.

Ramírez, Carmen Luz, 1997: "Algunos aspectos de la catequesis parroquial del siglo XIX en Chile", Anuario de Historia de la Iglesia en Chile 15, 79-100.

ReYes, Fermín de Ios, 2000: El libro en España y América. Legislación y censura. Siglos XV-XVIII I, Madrid: Arco/Libros.

RIDRUeJo, Emilio, 2007: El arte de la lengua de Chile de Luis de Valdivia, Madrid: AECID.

Ridruejo, Emilio, 2009: "Notas sobre el verbo millcayac según el Arte (1607) de Luis de Valdivia”, Revista Internacional de Lingüística Iberoamericana 13, 137-159.

Salinas, Maximiliano, 1991: "El evangelio, el imperio español y la opresión contra los mapuches: el padre Luis de Valdivia en Chile, 1593-1619" en J. Pinto, M. Salinas y R. Foerster: Misticismo y violencia en la Temprana Evangelización de Chile, Temuco: Universidad de La Frontera, 71-167.

SCHÜLleR, Rudolf R., 1913a: "Discovery a fragment of the printed copy of the work on the Millcayac language by Luis de Valdivia. With a bibliographical notice", Papers. Peabody Museum of American Archaeology an Ethnology III/5, 220-258. 
SchülleR, Rudolf R., 1913b: "Zur sprachlichen Stellung der Millcayac-Indianer", Internationales Archiv für Ethnographie XXI, 177-188.

Ser Pérez, Fernando del, 1998: "La provincia jesuítica de Castilla en el Archivum Romanum Societatis lesu", Cuadernos de Historia Moderna 20, 167-188.

Tovar, Antonio, 1984: Catálogo de las lenguas de América del Sur, Madrid: Gredos.

Viegas Barros, Pedro, 2009: "Una propuesta de fonetización y fonemización tentativas de las hablas huarpes" [disponible en http://www.adilq.com.ar/FONEMIZACION\%2OHUARPE.pdf, fecha de consulta: 12 de agosto de 2012].

ViñazA, Conde de, 1892: Bibliografía española de lenguas indígenas de América, Madrid: Sucesores de Rivadeneyra.

Zapater, Horacio, 1992: La búsqueda de la paz en la guerra de Arauco: padre Luis de Valdivia, Santiago de Chile: Andrés Bello.

ZWARTJES, Otto, 2000: "Modo, tiempo y aspecto en las gramáticas de las lenguas mapuche, millcayac, y guaraní de Luis de Valdivia y Antonio Ruiz de Montoya: La categoría de los 'tiempos mixtos'” en O. Zwartjes (dir.): Las gramáticas misioneras de tradición hispánica, Amsterdam/ Atlanta: Rodopi, 205-254. 